\title{
LINHA DE BASE AVALIATIVA DA IMPLANTAÇÃO DA POLÍTICA NACIONAL DE SAÚDE INTEGRAL DA POPULAÇÃO NEGRA EM UM MUNICÍPIO DO ESTADO DA BAHIA
}

\author{
Mardini Rafaela Silva Pereira ${ }^{1}$; Silvone Santa Bárbara da Silva Santos ${ }^{2}$ \\ 1. Bolsista PIBIC/Fapesb, Graduando em Enfermagem, Universidade Estadual de Feira de Santana, e-mail: \\ mardinirafaela@gmail.com \\ 2. Orientador, Departamento de Saúde, Universidade Estadual de Feira de Santana, e-mail: \\ silvone.santabarbara@gmail.com
}

PALAVRAS-CHAVE: Saúde da população negra; Políticas de saúde; Avaliação.

\section{INTRODUÇÃO}

No estado da Bahia, 79,1\% da população é constituída de negros (IBGE, 2010) e, assim como nos outros estados brasileiros, indivíduos brancos e negros ocupam espaços sociais diferentes o que reflete nos indicadores sociais, visto que os negros possuem os piores indicadores para escolaridade, piores postos de trabalho, além de terem um menor acesso a bens e serviços sociais, incluindo a saúde.

Para minimizar os problemas relacionados à saúde da população negra, foi instituída em 2009 a Política Nacional de Saúde da População Negra que se expressa através de três dimensões definidas: acesso às ações e serviços de saúde; gestão e pesquisa (SANTOS;ARAÚJO, 2014).

Nesse sentido, foi elaborada a seguinte questão de pesquisa: qual o grau de implantação da Política Nacional de Atenção Integral da Saúde da População Negra no município de Salvador, Bahia, no ano de 2016, no que se refere à dimensão da gestão? Assim, o estudo tem como objetivo identificar o grau de implantação da Política Nacional de Saúde Integral da População Negra no município de Salvador, a partir da análise de indicadores de gestão da saúde.

\section{METODOLOGIA}

Trata-se de um estudo de linha de base avaliativa, utilizando-se um plano de indicadores elaborados para esta pesquisa que contempla a dimensão da gestão. Para avaliar o grau de implantação da PNNSIPN em Salvador, foram utilizados seis indicadores de gestão, do tipo quantitativo, associados a quatro variáveis: educação permanente, controle social, processo decisório e disponibilização de recursos financeiros. A coleta de dados foi feita a partir da análise documental, sendo utilizados como instrumentos para análise deste estudo o Plano Municipal de Saúde (2010-2013), Plano Plurianual (2010-2013) e a página eletrônica do Conselho Municipal de Saúde. A análise documental foi norteada por variáveis e indicadores elaborados para esta pesquisa, associada às perguntas avaliativas e parâmetros, contempladas na dimensão da gestão.

\section{RESULTADOS E DISCUSSÃO}

A partir da coleta de dados, foram analisados seis indicadores para identificar o grau de implantação da PNSIPN em Salvador, na dimensão da gestão. Desses, quatro obtiverem pontuação positiva, um obteve pontuação zero e um não se aplicou à 
pontuação, pois não foi analisado devido o não acesso aos dados relacionados ao indicador. Dessa forma, identifica-se que o grau de implantação da PNSIPN no município de Salvador pode ser classificado como implantada, segundo o modelo proposto por Oliveira, Natal e Camacho, visto que o escore obtido pelo município foi com ponto de corte de $80 \%$ (Quadro 1).

Quadro 1 - Grau de implantação da Política Nacional de Saúde Integral da População Negra em Salvador, Bahia.

\begin{tabular}{|c|c|c|c|c|}
\hline INDICADOR & $\begin{array}{c}\text { PERGUNTA } \\
\text { AVALIATIVA }\end{array}$ & PARÂMETRO & $\begin{array}{c}\text { PONTUA- } \\
\text { ÇÃO }\end{array}$ & $\begin{array}{l}\text { PERCEN- } \\
\text { TUAL }\end{array}$ \\
\hline $\begin{array}{l}\text { Existência de } \\
\text { iniciativas de } \\
\text { educação } \\
\text { permanente } \\
\text { voltadas para a saúde } \\
\text { da } \\
\text { população } \\
\text { negra }\end{array}$ & $\begin{array}{l}\text { Quantas foram as } \\
\text { capacitações que os } \\
\text { trabalhadores de } \\
\text { saúde receberam } \\
\text { durante o período de } \\
2010 \text { a } 2015, \\
\text { enfocando a saúde da } \\
\text { população negra? }\end{array}$ & $\begin{array}{l}\text { Pelo menos } 01 \\
\text { capacitação por } \\
\text { ano ofertada pelo } \\
\text { município aos } \\
\text { trabalhadores da saúde } \\
\text { desde a } \\
\text { implantação da } \\
\text { política de saúde } \\
\text { da população } \\
\text { negra }\end{array}$ & 1 & $20 \%$ \\
\hline $\begin{array}{l}\text { Representantes de } \\
\text { entidades negras } \\
\text { como conselheiros de } \\
\text { saúde. }\end{array}$ & $\begin{array}{l}\text { Quantos representantes } \\
\text { de organizações de } \\
\text { movimentos negros, } \\
\text { mulheres } \\
\text { quilombolas negras, } \\
\text { religiões de matriz } \\
\text { africana participam do } \\
\text { conselho municipal de } \\
\text { saúde. }\end{array}$ & $\begin{array}{l}\text { Pelo menos um } \\
\text { representante de uma } \\
\text { dessas organizações no } \\
\text { conselho municipal de } \\
\text { saúde. }\end{array}$ & 1 & $20 \%$ \\
\hline $\begin{array}{l}\text { Projeto ou plano de } \\
\text { ação de saúde voltado } \\
\text { para a população } \\
\text { negra apresentado no } \\
\text { conselho municipal de } \\
\text { saúde }\end{array}$ & $\begin{array}{l}\text { Foram apresentados ao } \\
\text { conselho municipal de } \\
\text { saúde projetos ou plano } \\
\text { de ação voltado para a } \\
\text { saúde da população } \\
\text { negra? }\end{array}$ & $\begin{array}{l}\text { Apresentação de pelo } \\
\text { menos 1 projeto ou } \\
\text { plano de ação voltado } \\
\text { para a saúde da } \\
\text { população negra no ano } \\
\text { de } 2010 \text {. }\end{array}$ & $\begin{array}{l}\text { Não se } \\
\text { aplica }\end{array}$ & $\begin{array}{l}\text { Não se } \\
\text { aplica }\end{array}$ \\
\hline $\begin{array}{l}\text { Processo decisório } \\
\text { baseado nas diretrizes } \\
\text { propostas no Plano } \\
\text { Municipal de Saúde. }\end{array}$ & $\begin{array}{l}\text { Existem ações de saúde } \\
\text { para a população negra } \\
\text { definidas no Plano } \\
\text { Municipal de Saúde? }\end{array}$ & $\begin{array}{l}\text { Ações de saúde para a } \\
\text { população } \\
\text { definidas no nra } \\
\text { Municipal de Saúde. }\end{array}$ & 1 & $20 \%$ \\
\hline $\begin{array}{l}\text { Existência de } \\
\text { instancia de promoção } \\
\text { da equidade em Saúde }\end{array}$ & $\begin{array}{l}\text { Existem instancias de } \\
\text { promoção da equidade } \\
\text { em Saúde no } \\
\text { município? }\end{array}$ & $\begin{array}{l}\text { Existência de } \\
\text { municípios por estado } \\
\text { com } 150 \text { mil ou mais } \\
\text { habitantes em comando } \\
\text { único com instancia de } \\
\text { promoção da equidade } \\
\text { em saúde implantado }\end{array}$ & 0 & $0 \%$ \\
\hline $\begin{array}{l}\% \text { de recursos } \\
\text { disponibilizados para } \\
\text { a PNSIPN }\end{array}$ & $\begin{array}{lr}\text { Existem recursos } \\
\text { financeiros } \\
\text { disponibilizados } \\
\text { PPA no para } \\
\text { implementação a } \\
\text { Política da } \\
\text { Integral da População } \\
\text { Negra? }\end{array}$ & $\begin{array}{l}\text { Existência de rubrica } \\
\text { no orçamento no PPA } \\
\text { referente às ações para } \\
\text { implementação da } \\
\text { Política de Saúde da } \\
\text { População Negra }\end{array}$ & 1 & $20 \%$ \\
\hline
\end{tabular}

Os achados deste estudo demonstram que o município de Salvador dispõe de planos de ações que visam contribuir para o combate ao racismo institucional. 
Entretanto, não foram encontradas ações de educação permanente voltadas para o combate às demais iniquidades em saúde que assolam a população negra.

A importância da educação permanente na implantação da PNSIPN no município de Salvador está associada às mudanças que a mesma provoca nos processos de formação, uma vez que trata-se de um instrumento utilizado para transformar o profissional de saúde em um profundo conhecedor de sua realidade local (MICCAS; BATISTA, 2014).

No que diz respeito ao controle social, neste estudo, observou-se que há participação de um representante de movimentos negros, quilombolas ou religiões de matriz africana no Conselho Municipal de Saúde. No entanto, a baixa representatividade de entidades negras no Conselho Municipal de Saúde do município de Salvador é evidenciada no estudo de Dantas et al. (2015), no qual os autores afirmam que essa baixa representatividade interfere na efetivação da PNSIPN na Bahia.

No que tange à existência de projeto ou plano de ação de saúde voltada para a população negra apresentado no CMS, neste estudo não foi possível ter acesso às atas das reuniões ocorridas e consequentemente ter conhecimento das pautas das reuniões do Conselho. No entanto, Dantas et al. (2015) afirmam que o CMS de Salvador dispõe de propostas direcionadas ao combate ao racismo: "Sensibilizar, capacitar e comprometer as ouvidorias do município para a apuração e encaminhamento das denúncias de racismo na Secretaria Municipal de Saúde.”

Neste estudo, o processo decisório foi verificado a partir da existência de ações estratégicas que têm por objetivo implementar a política da população negra no município de Salvador. No que diz respeito à implementação da política, alguns autores afirmam que existem diferentes fatores que podem ser prejudiciais ao processo decisório, tais como a imprevisibilidade relativa aos recursos ou mudanças próprias da dinâmica da realidade; conflitos de interesse entre os governantes e entre estes e quem presta ou executa os serviços; fragmentação de papeis das autoridades, tanto relativos aos setores, quanto aos diferentes níveis de governo comprometidos na execução das políticas públicas (KLEBA; ZAMPIROM; COMERLATTO, 2015; LINDBLOM, 1981).

Quanto às questões financeiras, os resultados deste estudo permitiram verificar previsão orçamentária de recursos para o desenvolvimento de ações que contribuem para a implantação da PNSIPN. Do mesmo modo que a PNSIPN, a Política Nacional de Promoção da Saúde (PNPS) busca reduzir as iniquidades em saúde, visando o empoderamento de indivíduos ou grupos (MALTA et al., 2014). No caso da PNPS, Malta et al. (2014) em seu estudo discutem alguns pontos que favorecem o fortalecimento da Política, dentre eles está o financiamento.

\section{CONCLUSÃO}

A partir dos resultados encontrados no presente estudo, foi possível construir uma linha de base avaliativa que poderá subsidiar avaliações futuras sobre a implantação da PNSIPN no município de Salvador. Assim, a partir da análise dos indicadores de gestão da saúde, citados neste estudo, conclui-se que no município de Salvador a PNSIPN classifica-se como implantada, tendo em vista o escore de 83,3\% obtido na avaliação dos indicadores elaborados para esta pesquisa. 


\section{REFERÊNCIAS}

DANTAS, I. S. et al. Estruturação dos Conselhos Municipais de Saúde na Bahia para o controle social: um estudo de linha de base. Revista da Associação Brasileira de Pesquisadores/as Negros/as (ABPN), v. 7, n. 16, p. 52-73, 2015.

KLEBA, M. E.; ZAMPIROM, K.; COMERLATTO, D. Processo decisório e impacto na gestão de políticas públicas: desafios de um Conselho Municipal de Saúde. Saúde e Sociedade, v. 24, n. 2, p. 556-567, 2015.

MALTA, D. C. et al. A implementação das prioridades da Política Nacional de Promoção da Saúde, um balanço, 2006 a 2014. Ciência \& Saúde Coletiva, v. 19, n. 11, 2014.

MICCAS, F. L.; BATISTA, S. H. S. S. Educação permanente em saúde: metassíntese. Revista de Saúde Pública, v. 48, n. 1, 2014.

SANTOS, S.S.B.S; ARAÚJO,E. M. Avaliação da implantação da Política de Saúde da População Negra na Bahia, Sergipe e São Paulo. In: ARAÚJO,E. M. Avaliação da Atenção à Saúde da População Negra e a Intersecção do Racismo sobre as Práticas de Cuidado em Estados do Nordeste e do Sudeste Brasileiro. Projeto CNPq/MS/SCTIE/DECIT/ SGEP/DAGEP No 21/2014 - Saúde da População Negra no Brasil. Universidade Estadual de Feira de Santana, Bahia, 2014. 